\title{
Downregulation of human intercellular adhesion molecule-1 attenuates the metastatic ability in human breast cancer cell lines
}

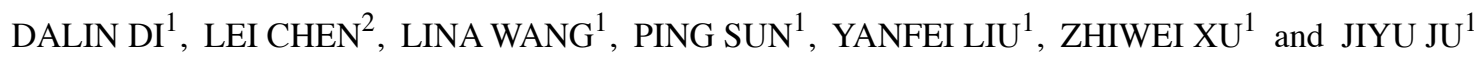 \\ ${ }^{1}$ Department of Immunology, Weifang Medical University; ${ }^{2}$ Department of Hematology, \\ Affiliated Hospital of Weifang Medical University, Weifang, Shandong 261053, P.R. China
}

Received September 30, 2015; Accepted December 9, 2015

DOI: 10.3892/or.2016.4543

\begin{abstract}
Intercellular adhesion molecule-1 (ICAM-1) is a cell surface glycoprotein that belongs to immunoglobulin superfamily and plays an important role in tumor cell expansion or metastasis. However, the detailed mechanisms of ICAM-1 in breast cancer remain unclear. In this study, we evaluated the expression level of ICAM-1 in breast cancer using tissue microarray and clinical tissue specimens by immunohistochemical method, and the results revealed that ICAM-1 is highly expressed in the breast cancer tissues. To investigate whether ICAM-1 can affect the metastasis ability in breast cancer, we knocked down ICAM-1 expression in breast cancer cell line MCF-7 by using lentivirus-mediated RNA interference (RNAi). As a result, we stably silenced ICAM-1 expression in MCF-7 cells by infection with lentivirus expressing green fluorescent protein (GFP), the change of metastatic ability of MCF-7 cells was assessed by wound-healing assay, Transwell assay or clone formation assay. Our results showed that silencing of ICAM-1 can inhibit the metastatic ability of MCF-7 cell lines in vitro significantly, and the decreased migration and invasion was accompanied by a reduction of MMP-14. These results implying that ICAM-1 might be involved in the progression of breast cancer metastasis and lentivirus-mediated silencing of ICAM-1 might be a potential therapeutic approach for the treatment of breast cancer.
\end{abstract}

\section{Introduction}

Breast cancer is the most common cancer in women both in developed or less developed world and is estimated that over 508,000 women die due to it each year according to WHO statistics (Global Health Estimates, WHO 2013) $(1,2)$, breast cancer is recognized as the fifth most frequent cause of cancerassociated mortality in women worldwide (3). With advances in treatment of breast cancer such as cytotoxic chemotherapy,

Correspondence to: Dr Jiyu Ju, Department of Immunology, Weifang Medical University, Weifang, Shandong 261053, P.R. China E-mail: jujiyu@wfmc.edu.cn

Key words: ICAM-1, lentivirus, breast cancer, metastasis antihormonal therapy or radiation therapy, the outcomes of patients have improved significantly in recent years. However, recurrent metastatic breast cancer is still incurable and only $3 \%$ of patients with metastatic disease achieve a complete response for $>5$ years (4). Metastatic breast cancer is a complicated and multi-step malignant tumor involving a biological process that has many stages, and steps, and multiple genes and $90 \%$ of cancer-associated deaths are related to cancer cells metastasis. Growing evidence has demonstrated that the change of intercellular adhesion molecule play an important role in the metastasis of breast cancer (5).

Intercellular adhesion molecule-1 (ICAM-1) is a cell surface glycoprotein belonging to immunoglobulin superfamily widely expressed on leukocytes, fibroblasts, keratinocytes, endothelial or epithelial cells and can be upregulated in response to various of inflammatory mediators (6). Previous studies have shown that ICAM-1 plays an important role in tumor cell adhesion, and metastasis progression (7). However, the exact role of ICAM-1 during the process of breast cancer is not well known and there are various reports on whether ICAM-1 can facilitate breast cancer progression. Some argue that ICAM-1 is low expressed in breast cancer tissues than that of benign breast cells or normal breast tissues and in this way escape the lysis by CTLs or NK cells, but others argue that ICAM-1 was overexpressed in breast cancer and promoted the development of tumors $(8,9)$. In previous work carried out on the BCSC-1 gene (breast cancer candidate inhibiting protein 1) it was regarded as a melanoma tumor suppressor $(10,11)$, we found that the migration and invasion ability of breast cancer cell were reduced significantly after transfected with the BCSC-1 gene, then we found that ICAM-1 was affected most significantly by qRT-PCR method. However, the exact role of ICAM-1 in breast cancer remains unclear and further investigation is required to understand the role and molecular mechanisms of ICAM-1 in breast cancer. To this end, we first stably silenced ICAM-1 expression in the breast cancer MCF-7 cells by infection with lentivirus, then we examined the effects of ICAM-1 on MCF-7 cell metastasis in vitro. Previous research has indicated that MMP-14 which belong to the gelatinase MMP subfamily was overexpressed on different tumor cell surfaces including breast cancer and has a critical role for tumor invasion or metastasis $(12,13)$, so the changes of MMP-14 in MCF-7 cells after infected by ICAM-1 lentivirus was also assessed in this study. 
Table I. Target genes and sequences of lentiviral shRNAs.

\begin{tabular}{llll}
\hline Target gene & Name & Target sequences & Site \\
\hline Human ICAM-1 & Lv-sh1 & 5'-aagaaccttacctacgctgc-3' & $385-405$ \\
Human ICAM-1 & Lv-sh2 & 5 '-gcctcagcacgtacctcta-3' & $940-962$ \\
Human ICAM-1 & Lv-sh3 & 5 '-aacgtgattctgacgaagccaga-3' & 1490-1508 \\
Negative control & Lv-shNC & 5'-cctaaggttaagtcgccctc-3' & Nonsense \\
\hline
\end{tabular}

Table II. Expression of ICAM-1 in breast cancers.

\begin{tabular}{|c|c|c|c|c|c|c|c|c|c|c|c|}
\hline \multirow[b]{3}{*}{ Sample } & \multirow[b]{3}{*}{$\mathrm{N}$} & \multicolumn{8}{|c|}{ ICAM-1 immunostaining } & \multirow[b]{3}{*}{$\chi^{2}$-value } & \multirow[b]{3}{*}{ P-value } \\
\hline & & \multicolumn{2}{|c|}{$\begin{array}{c}\text { Negative } \\
(-)\end{array}$} & \multicolumn{2}{|c|}{$\begin{array}{c}\text { Weak } \\
(+)\end{array}$} & \multicolumn{2}{|c|}{$\begin{array}{c}\text { Moderate } \\
(++)\end{array}$} & \multicolumn{2}{|c|}{$\begin{array}{c}\text { Strong } \\
(+++)\end{array}$} & & \\
\hline & & $\mathrm{N}$ & $\%$ & $\mathrm{~N}$ & $\%$ & $\mathrm{~N}$ & $\%$ & $\mathrm{~N}$ & $\%$ & & \\
\hline Breast cancers & 104 & 6 & 5.77 & 26 & 25 & 30 & 28.85 & 42 & 40.38 & & \\
\hline Adjacent non-tumor tissues & 38 & 18 & 47.37 & 11 & 28.94 & 6 & 15.79 & 3 & 7.89 & 39.81 & $<0.001$ \\
\hline
\end{tabular}

\section{Materials and methods}

Cells and cell culture. Human breast cancer cells MCF-7 and human embryonic kidney HEK293T cells were cultured in DMEM (Invitrogen, Carlsbad, CA, USA) media containing 10\% fetal bovine serum (FBS) (Gibco), $100 \mathrm{IU} / \mathrm{ml}$ penicillin and $100 \mu \mathrm{g} / \mathrm{ml}$ streptomycin. All cells were kept at $37^{\circ} \mathrm{C}$ and in $5 \%$ carbon dioxide humidified atmosphere.

Tissue microarrays and clinical tissue specimens for immunohistochemistry. Tissue microarray contain 69 cases of breast cancer tissues and 3 cases of normal breast tissues was purchased from Alenabio Co. (Xi'an, China). For further confirmation, we also gathered 35 cases of pathologically and clinically confirmed breast cancer from breast surgery centre of Weifang People's Hospital. The breast cancer tissues and adjacent non-tumor tissues were obtained before the patients received any treatment. All patients above were required to sign an informed consent and our experiments were approved by the institutional ethics committee. The SP immunohistochemical staining was performed according to the manufacturer's instructions (Bioss, Beijing, China). Briefly, tissue microarray of breast cancer was put into citrate buffer (pH 6.0) at $100^{\circ} \mathrm{C}$ for $30 \mathrm{~min}$ for antigen retrieved, sequential incubations with mouse anti-human ICAM-1 antibody (Cell Signaling Technology, Inc., Danvers, MA, USA) at 1:500 dilution, secondary antibody and finally chromogenic DAB substrate (ZSGB-BIO, Beijing, China). The degree of immunostaining of the tissue microarray was viewed and scored separately by three independent investigators. Cytoplasmic and membranous staining intensity were categorized as follows: absent staining, 0; weak, 1; moderate, 2; and strong, 3 . The percentage of positive stained cells were categorized as: no staining, $0 ; 0-24 \%, 1 ; 25-49 \%, 2 ; 50-74 \%$, 3; and $75-100 \%$, 4. The total score was calculated by multiplying the staining intensity and percentage of positive stained cells. The final score $<2$ was negative (-); 3-4 was weak (+); 6-8 was moderate $(++)$ and 9-12 was strong $(+++)$.

Construction of ICAM-1 shRNA lentivirus and MCF-7 cell infection. Three shRNA sequences targeting human ICAM-1 and a negative control sequence (Table I) were designed and cloned into the pLKO.1-SP6-PGK-GFP vector. For lentivirus packaging, HEK293T cells were transfected with ICAM-1 shRNA or control shRNA together with two helper plasmids (psPAX2 and pMD2.G) using Lipofectamine ${ }^{\mathrm{TM}} 2000$ (Invitrogen) according to the manufacturer's instructions. Four days after transfection, the supernatant of HEK293T cells that containing packaged lentivirus was collected and passed through $0.45-\mu \mathrm{m}$ filters. To infect MCF-7 cells, lentivirus particles were added to the culture medium at a multiplicity of infection (MOI) of 5. The efficiency of infection was determined by GFP percentage by flow cytometry (BD FACSCalibur; BD Biosciences, Baltimore, MD, USA) four days after lentivirus infection.

RNA extraction and quantitative real-time PCR ( $q R T-P C R)$. Total RNA of MCF-7 cells were extracted with TRIzol solution (Takara Bio, Inc., Otsu, Japan) at $24 \mathrm{~h}$ after infection and reverse transcribed to cDNA using a PrimerScript RT reagent kit (Takara Bio, Inc.) by the manufacturer's instructions. $\beta$-actin was used as a normalization control. Primers were chemically synthesized by BioSune Biotechnology (Jinan, China). All primer pairs used for Real-time PCR were designed according to the sequences from GenBank (Table II). Real-time PCR was performed using SYBR Premix Ex Taq (Takara Bio, Inc.) on an CFX96 real-time PCR detection system (Bio-Rad, Berkeley, CA, USA). The PCR conditions were as follows: predegeneration at $94^{\circ} \mathrm{C}$ for $1 \mathrm{~min}$, then 35 cycles of denaturation at $94^{\circ} \mathrm{C}$ for $30 \mathrm{sec}$, renaturation at $55^{\circ} \mathrm{C}$ for $30 \mathrm{sec}$, extension at $72^{\circ} \mathrm{C}$ for $45 \mathrm{sec}$. The relative mRNA expression level was determined by cycle threshold $(\mathrm{Ct})$ normalized with 


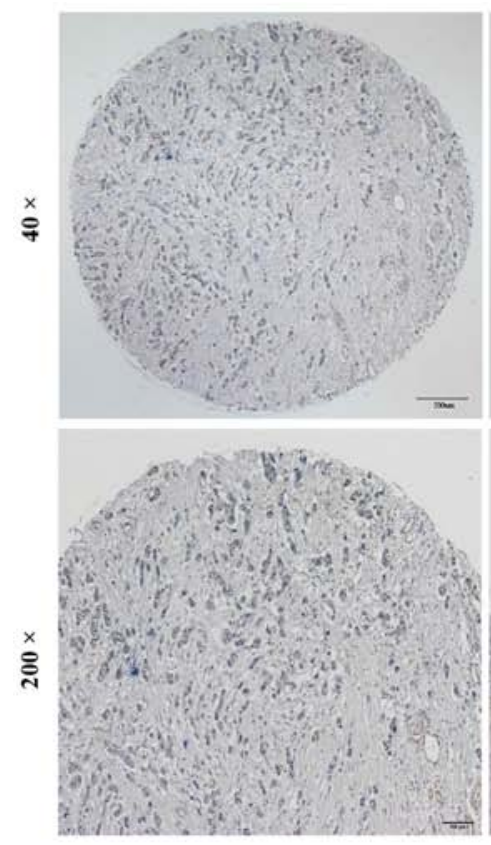

Negative (-)

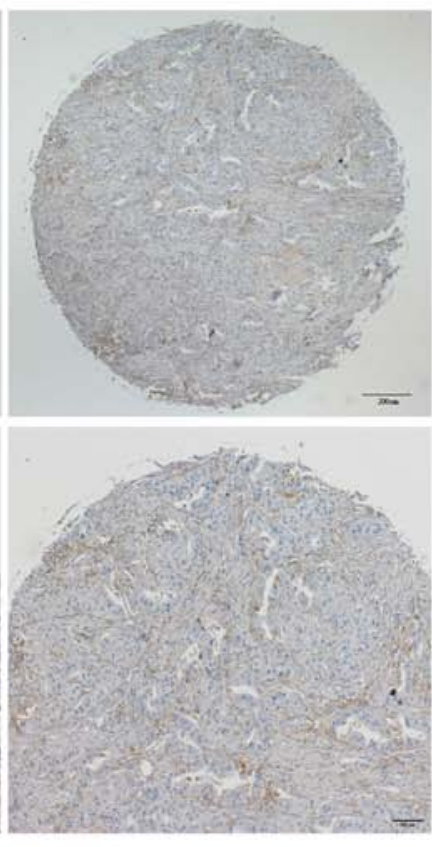

Weak (+)

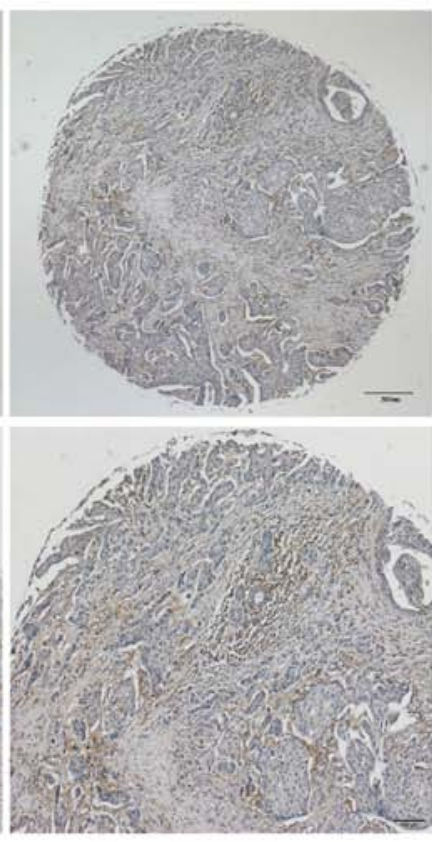

Moderate (++)

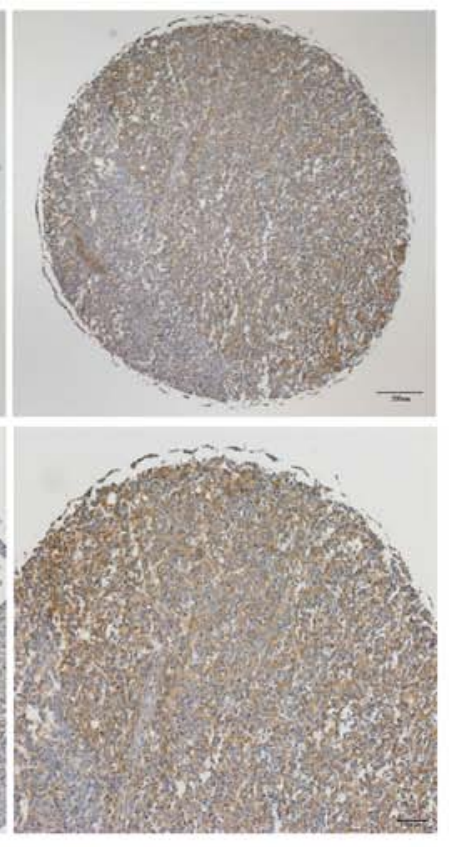

Strong $(+++)$

Figure 1. ICAM-1 expression in breast cancer and normal breast tissues. Tissue microarrays contain both breast cancer samples and normal breast tissue samples immunohistochemically stained using antibody against ICAM-1 at low (x40) and high (x200) magnification, respectively, under a light microscope.

$\beta$-actin using the $2-\Delta \Delta \mathrm{Ct}$ formula. (CT, cycle threshold) where $\Delta \mathrm{CT}=\mathrm{CT}$ (target gene) - CT $(\beta$-actin).

Sequences of sense and antisense primers used for qRT-PCR were as follows: ICAM-1-forward: 5'-ATGCCCA GACATCTGTGTCC-3', ICAM-1-reverse: 5'-GGGGTCT CTATGCCCAACAA-3'; $\beta$-actin-forward: 5'-CCTAGAA GCATTTGCGGTGG-3', $\beta$-actin-reverse: 5'-GAGCTACG AGCTGCCTGACG-3'.

Western blot analysis. Four days after lentivirus infection, MCF-7 cells were washed by PBS and harvested, the protein concentration of each group were determined using BCA assay kit (Beyotime Institute of Biotechnology, Haimen, China). Subsequently, $40 \mu \mathrm{g}$ protein per lane was separated by $10 \%$ SDS-PAGE gel and transferred to NC membranes. The $\mathrm{NC}$ membranes (Beyotime Institute of Biotechnology) were blocked by $5 \%$ skim milk for $1 \mathrm{~h}$ and incubated with primary antibodies to ICAM-1 (Signaling Technology, Inc., 1:1000), MMP-14 (Abcam, Cambridge, MA, USA, 1:1000) and $\beta$-actin (Beyotime Institute of Biotechnology, 1:500) overnight, then incubated with their respective secondary antibody for $2 \mathrm{~h}$. All NC membranes were detected by chemiluminescence (ECL, Sangon Biotech, Shanghai, China) for $5 \mathrm{~min}$ and exposed to $\mathrm{X}$-ray film for 5-10 $\mathrm{min}$.

Wound-healing assay. For wound-healing assay, $\mathrm{MCF}-7$ cells were plated into 6-well plates at a density of $1 \times 10^{5} / \mathrm{ml}$ and grown to form a confluent monolayer, wounds were made with sterile pipette tips and photographs of the wounds were taken at indicated time points $(0,24$ and $48 \mathrm{~h})$.

Cell migration and invasion assay. MCF-7 cells $\left(5 \times 10^{5}\right)$ were plated in $300 \mu \mathrm{l}$ of serum-free medium and placed into cell chambers ( $8-\mu \mathrm{m}$ pore size, Corning) coated with (Invasion) or without (migration) Matrigel (BD Biosciences), then incubated for $24 \mathrm{~h}$. Cells in the upper filters (inside the chambers) were removed by a sterile swab, the migrated or invaded cells in the lower filters (outside the chambers) were fixed by methanol for $2 \mathrm{~h}$, and stained with crystal violet. The number of migrated or invaded cells in five random optical fields were counted under a microscope.

Colony formation assay. Four days after lentivirus infection, $300 \mathrm{MCF}-7$ cells of Lv-sh3 group and NS group were seeded into different wells of 6-well plates, respectively, and cultured at $37^{\circ} \mathrm{C}$ in an incubator for $\sim 14$ days until most single colonies had $>50$ cells. All the colonies were washed by PBS and fixed with $4 \%$ methanol, then stained by Giemsa. Images were captured by light microscopy.

Statistical analysis. All the above experiments were performed three times (biological replicates), data are presented as mean \pm standard deviation (mean \pm SD) and analyzed by SPSS 10.0 software. $\chi^{2}$ test or Student's $t$ test were applied for statistical analysis and P-value $<0.05$ was considered as statistical significant in all cases.

\section{Results}

ICAM-1 is highly expressed in breast cancer. Previous studies indicated that the expression of ICAM-1 is involved in several carcinomas $(6,14,15)$. To investigate the function of ICAM-1 in breast cancer, we evaluated the expression of ICAM-1 in breast cancer tissue microarrays and clinical tissue specimens using immunohistochemical staining. Of the 104 breast cancer samples, $6(5.77 \%)$ were negative, $26(25 \%)$ were weakly positive, $30(28.85 \%)$ were moderately positive and $42(40.38 \%)$ were strongly positive. In normal breast tissue samples or adja- 
A
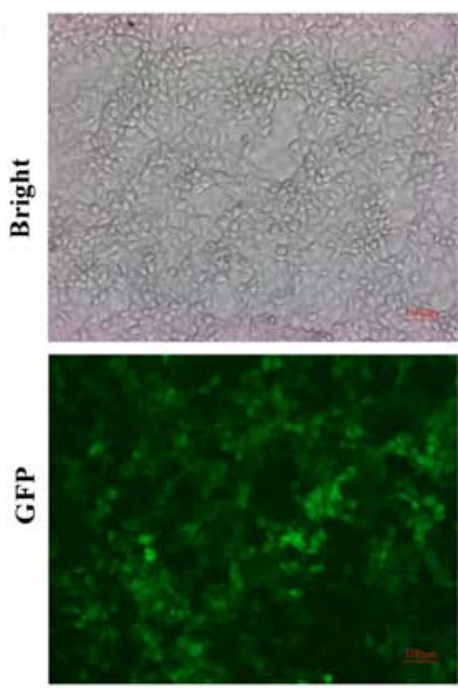

Lv-sh1
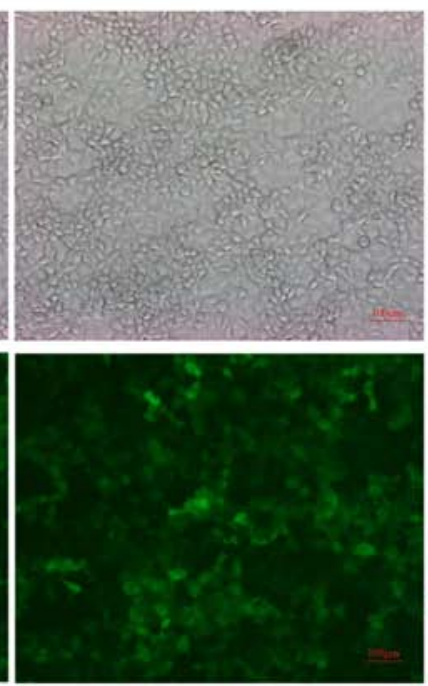

Lv-sh2
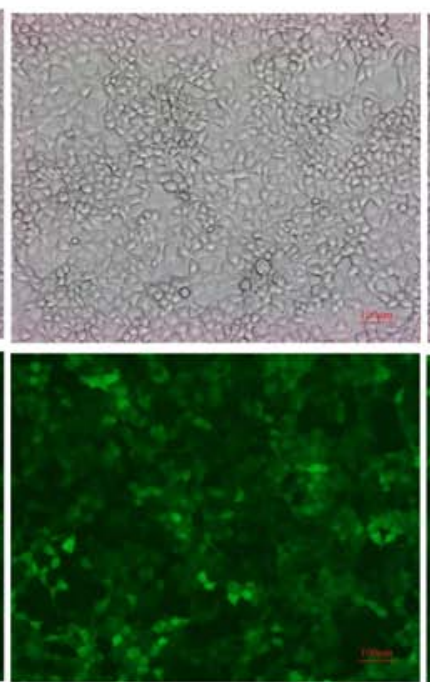

Lv-sh3
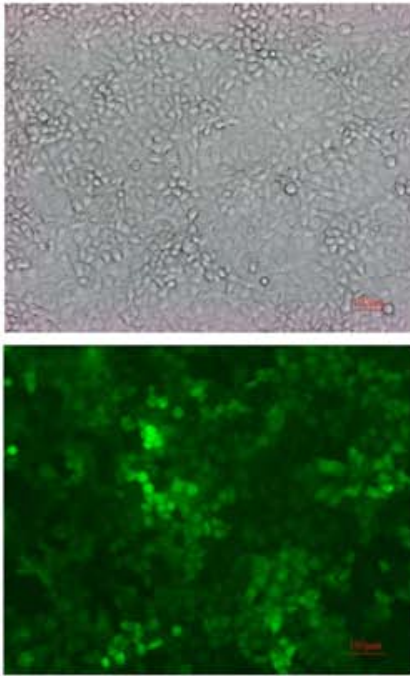

Lv-shNC

B
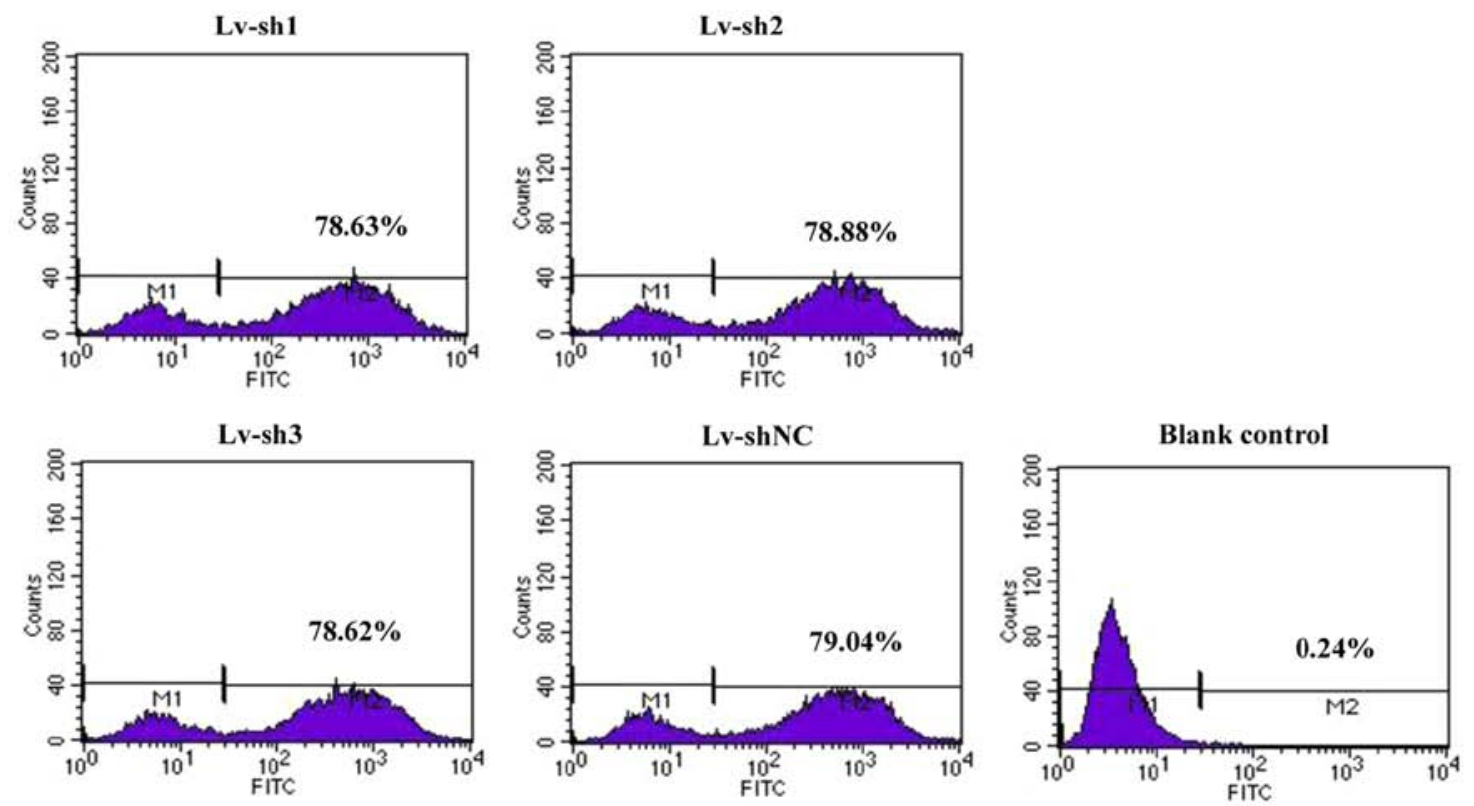

Figure 2. ICAM-1 lentivirus infection of MCF-7 cells and the efficiency. MCF-7 cells infected by ICAM-1 lentivirus. We examined the cells that emitting bright fluorescent green under a fluorescent microscope (A). To determine the exact infection efficiency of the lentivirus, we calculated the cell number that can fluoresce under flow cytometry (B).

cent non-tumor tissues, the results were: 18 (47.37\%) negative, $11(28.94 \%)$ weakly positive, $6(15.79 \%)$ moderately positive and 3 (7.89) strongly positive. The ICAM-1 expression level in breast cancer was significantly higher than the normal breast tissue or adjacent non-tumor tissues. These results suggest that ICAM-1 is highly expressed in breast cancer and might be involved in the pathogenesis of breast cancers (Fig. 1 and Table II).

ICAM-1 lentivirus infection of MCF-7 cells and the efficiency. To investigate the function of ICAM-1 in breast cancer cells, we used lentivirus-mediated RNAi technology, a powerful method which can knock down the endogenous ICAM-1 gene expression. Four days after lentivirus infection, MCF-7 cells were collected to calculate the number of fluorescentpositive cells by the FACS Calibur Flow Cytometry System. Fuorescence of GFP showed a high percentage of cells being infected by lentivirus (Fig. 2A) and results of FCM indicated the infection efficiency was $\sim 80 \%$ (Fig. 2B).

Lentivirus-mediated RNAi knockdown of ICAM-1 expression in MCF-7 cells. Four days after lentivirus infection, MCF-7 cells were harvested and the mRNA or protein level were detected by real-time PCR or western blotting method. Realtime PCR results indicated that the ICAM-1 mRNA level of MCF-7 cells in Lv-sh3 group were significantly reduced compared with Lv-shNC group (Fig. 3A, $\mathrm{P}<0.05$ or $\mathrm{P}<0.01$ ), Western blotting confirmed the silencing of ICAM-1 in MCF-7 cells (Fig. $3 \mathrm{~B}$ and $\mathrm{C}, \mathrm{P}<0.05$ ). These results suggest that the Lv-sh3 constructed efficiently and specifically knocked down expression of ICAM-1 in MCF-7 cells.

Suppression of ICAM-1 inhibits the ability of MCF-7 cell metastasis in vitro. To clarify the relationship between 

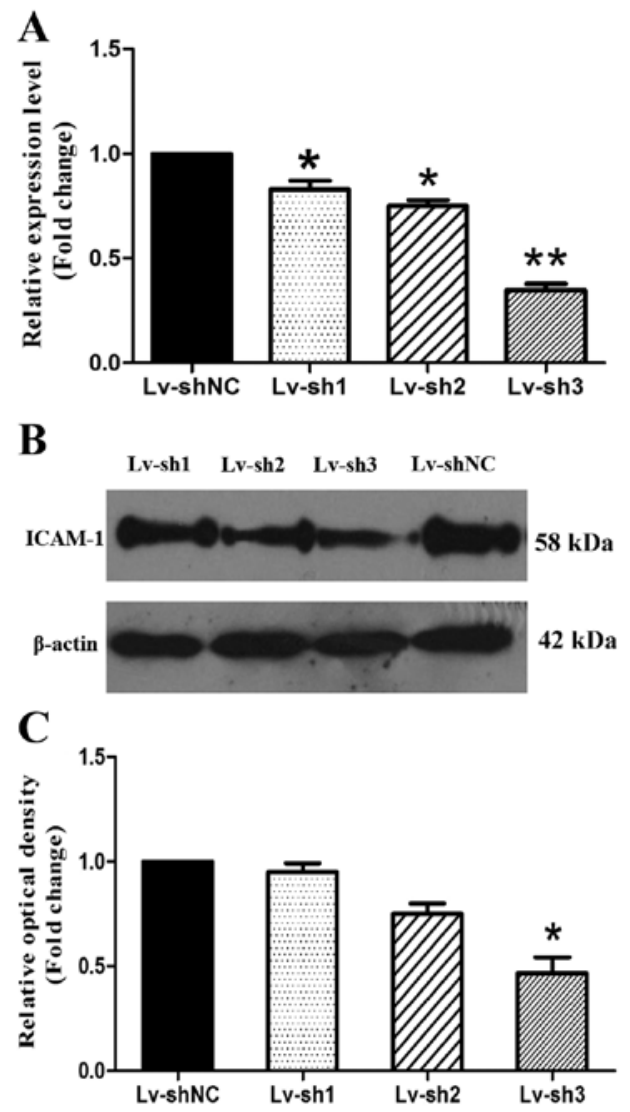

Figure 3. Effects of ICAM-1 lentivirus on ICAM-1 mRNA and protein expression in MCF-7 cells. Real-time PCR results showed the change of ICAM-1 mRNA expression level of MCF-7 cells in Lv-sh1, Lv-sh2 and Lv-sh3 group compared with Lv-shNC group (A). Western blotting results showed the downregulation of ICAM-1 protein level (B and $\mathrm{C}$ ). ${ }^{*} \mathrm{P}<0.05$ or ${ }^{* *} \mathrm{P}<0.01$ compared with Lv-shNC group.

ICAM-1 and the metastatic capability of MCF-7 cells, we stably suppressed ICAM-1 expression using lentivirus mediated RNAi technology. Suppression of ICAM-1 can inhibits metastasis ability of MCF-7 cells in vitro. In the migration test, on average $288.67 \pm 53.15$ cells in Lv-sh3 group migrated to the lower chamber, whereas $466.67 \pm 50.33$ cells in Lv-shNC group. In invasion test, there was on average $36 \pm 10.53$ cells in Lv-sh3 group and 67.67 \pm 7.5 in Lv-shNC group. The cell numbers of Lv-sh3 group that migrated through the membrane in migration or invasion test were significantly less than that of Lv-shNC group (Fig. 4A-C, P<0.05). In wound-healing assay, the average migration distance in $\mathrm{Lv}$-sh3 group was $90 \pm 5 \mu \mathrm{m}(24 \mathrm{~h})$ and $78.33 \pm 7.63 \mu \mathrm{m}(48 \mathrm{~h})$, significantly shorter than Lv-shNC group which migrated $131 \pm 6.55 \mu \mathrm{m}(24 \mathrm{~h})$ and $105 \pm 5 \mu \mathrm{m}(48 \mathrm{~h})$, respectively (Fig. 4D and E, $\mathrm{P}<0.05)$.

ICAM-1 gene silencing affects MMP-14 protein expression levels in MCF-7 cells. Matrix metalloproteinase (MMPs) are critical factors involved in tumor metastasis and we detected the influence of ICAM-1 gene silencing on MMP-14 protein expression levels by western blot analysis. As revealed in Fig. 5, we found that gene silencing of ICAM-1 can caused apparent decrease in MMP-14 expression levels, indicating that ICAM-1 mediated breast cancer cell metastasis might be linked with matrix metalloproteinase (MMP-14) (Fig. 5A and B, P<0.05).
ICAM-1 silencing reduces the colony formation ability of MCF-7 cells. Giemsa staining showed that the colony number in Lv-sh3 group was $58 \pm 7.94$ and significantly less than that in $\mathrm{Lv}$-shNC group (87.33 \pm 8.74$)$. Moreover, the size of the colony in Lv-sh3 group was reduced markedly compared with Lv-shNC group, indicating that ICAM-1 gene silencing could inhibit the colony formation ability of MCF-7 cells in vitro (Fig. 6A and B, $\mathrm{P}<0.05$ ).

\section{Discussion}

Tumor invasion or metastasis are major factors causing death of patients and majority of cancer patients succumb to the complications from distant metastases. Growing evidence has demonstrated that adhesion molecules expressed on tumor cell surface can mediate the adhesion between tumor cells and stromal or vascular endothelial cells and play an important role in the occurrence and development of tumors (16).

ICAM-1 is a cell surface glycoprotein that belongs to immunoglobulin superfamily, and expressed in a wide variety of lymphocytes or tumor cells. The ligand of ICAM-1 is lymphocyte function associated antigen 1 (LFA-1) and the interaction between ICAM-1 and its ligand can promote tumor metastasis through modulating cell-cell adhesion (17). However, the exact role of and function of ICAM-1 in the development of tumors has not been fully elucidated. It has been reported that the upregulation of ICAM-1 expression can increase the invasion and metastasis ability of tumor cells by promoting the adhesion between tumor cells and vascular endothelial or lymphatic endothelial cells, ultimately resulting in the distant metastasis of tumor cells (18). ICAM-1 is highly expressed in different human malignancies and believed to be involved in their pathogenesis. Previous research has shown that upregulation of ICAM-1 has been demonstrated in different malignant tumors including liver cancer, esophageal cancer, renal cell carcinoma, squamous carcinoma, gastric cancer or pancreatic cancer and associated with poor prognosis $(14,15,19-22)$.Under inflammatory environment, TGF (transforming growth factor) promoted osteosarcoma cell metastasis through the increasement of ICAM-1 by Akt signal pathway (23). Downregulation of ICAM-1 by short hairpin RNA (shRNA) transduction methods mitigated mouse colon cancer cell MC38 invasion ability (24). Proto oncogene K-ras could increase ICAM-1 expression in pancreatic acinar cells and the formation of precancerous lesions (25). ICAM-1 was found to be expressed at high levels in tumor-associated endothelium or tumor cells and was associated with epithelial carcinogenesis (26). Blocking NF- $\kappa \mathrm{B}$ pathway by Bay11-7082 can downregulate ICAM-1 expression and inhibit the disintegration of the lymph-endothelial barrier triggered by MCF-7 cells (27). However, data from other experiments regard that high expression of ICAM-1 enhances the anti-tumor ability through mediating the adhesion between tumor cells and cytotoxic T cells or NK cells (28), low expression of ICAM-1 allowing tumors to escape immune recognition (9). Breast cancer tissue or breast cancer cell lines showed low expression of ICAM-1 than that of normal breast epithelium or benign breast cells, the overexpression of ICAM-1 after TNF stimulation was able to help lymphokine-stimulated killer 
A
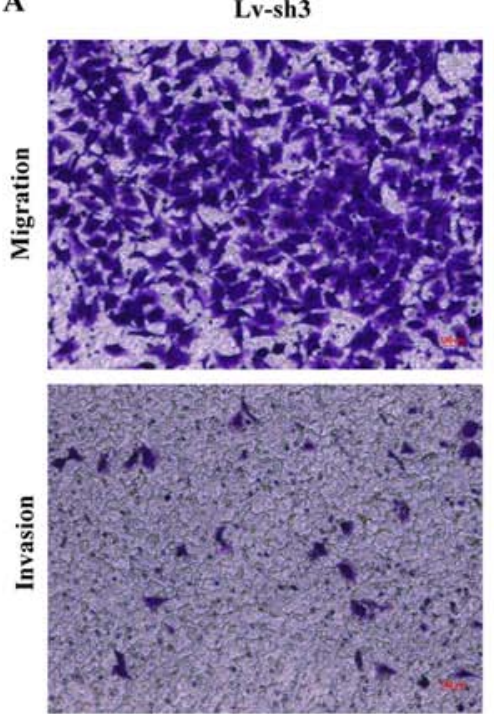

D
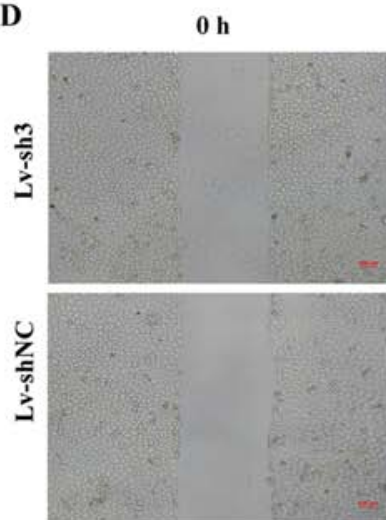

Lv-shNC
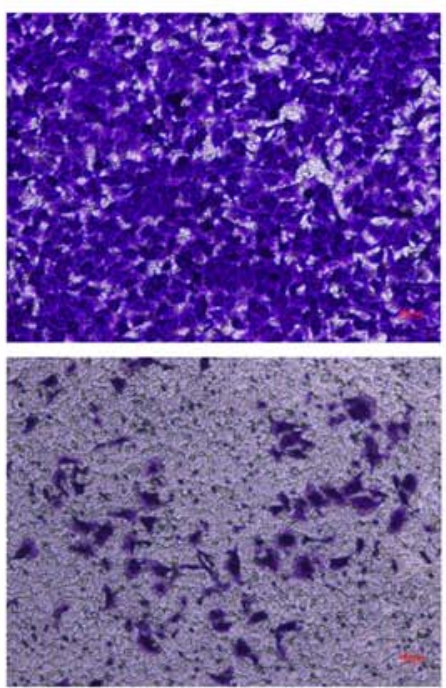

\section{B}
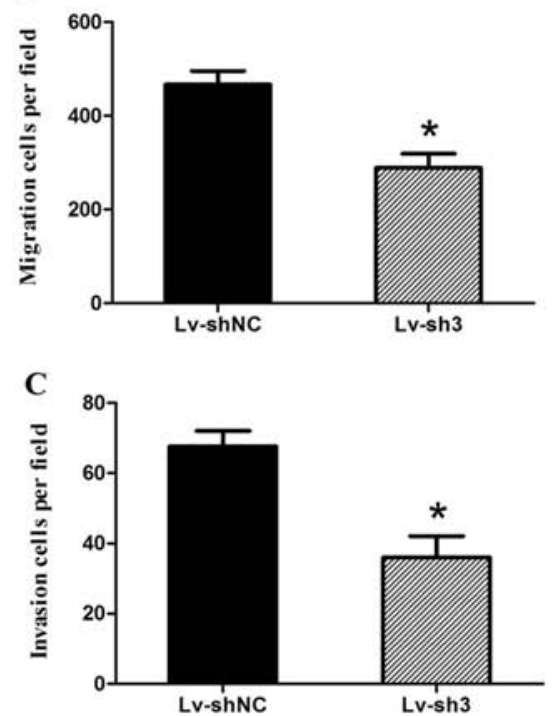

Figure 4. ICAM-1 lentivirus inhibits metastasis ability of MCF-7 cells in vitro. The number of MCF-7 cells in Lv-sh3 group that migrated through the membrane in migration or invasion test compared with that of Lv-shNC group (A-C). The migration distance of MCF-7 cells in Lv-sh3 group compared with that of $\mathrm{Lv}$-shNC group in wound-healing assay ( $\mathrm{D}$ and $\mathrm{E}) .{ }^{*} \mathrm{P}<0.05$ compared with $\mathrm{Lv}$-shNC group.

A
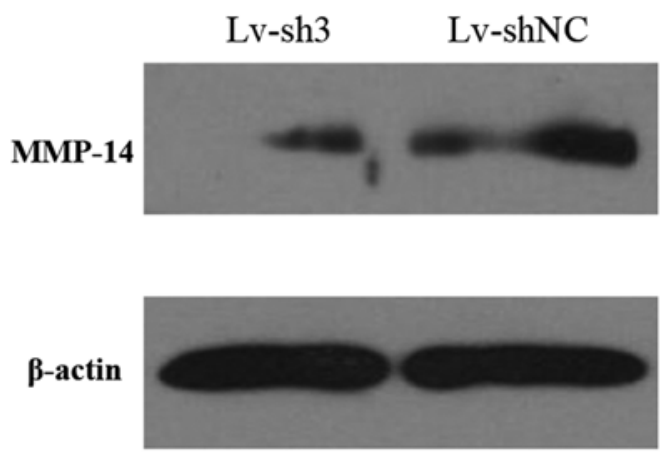

$66 \mathrm{kDa}$

$42 \mathrm{kDa}$

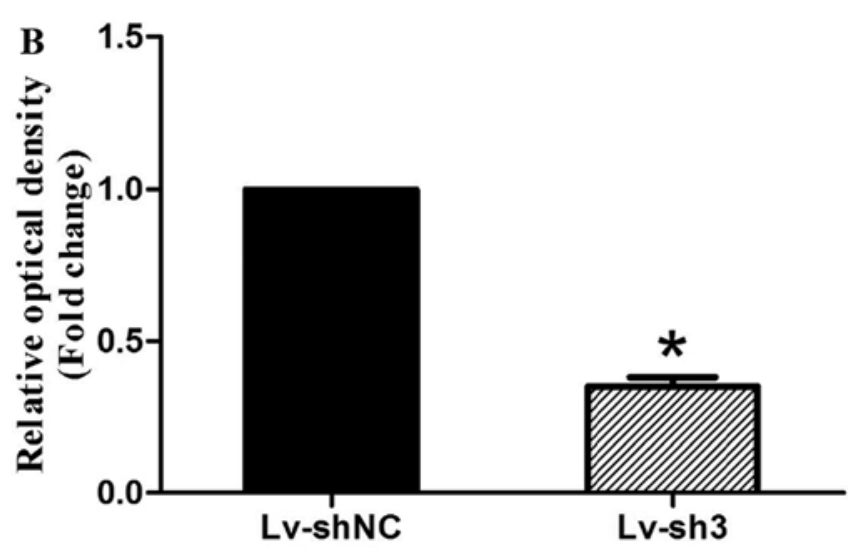

Figure 5. ICAM-1 lentivirus affects MMP-14 protein expression of MCF-7 cells. Western blotting results showed the change of MMP-14 protein expression level in Lv-sh3 group compared with that of Lv-shNC group (A and B). ${ }^{*} \mathrm{P}<0.05$ compared with $\mathrm{Lv}$-shNC group.

(LAK) cells to recognize breast cancer cells (29). The expression of ICAM-1 can be regulated by transcription factor E2F1 in prostate cells through $\mathrm{NF}-\kappa \mathrm{B}$ signaling pathway, silencing of E2F1 can increase ICAM-1 mediated leucocyte infiltration and inhibits tumor growth (30).
Other substances such as cannabidiol (CBD) elicits upregulation of ICAM-1 and inhibits lung cancer cell line A549, $\mathrm{H} 358$ or $\mathrm{H} 460$ metastasis, as a intermediate link in the CBD antimetastatic action on human lung cancer cells. ICAM-1 can increase cancer cell susceptibility to LAK cell-mediated cytol- 
A
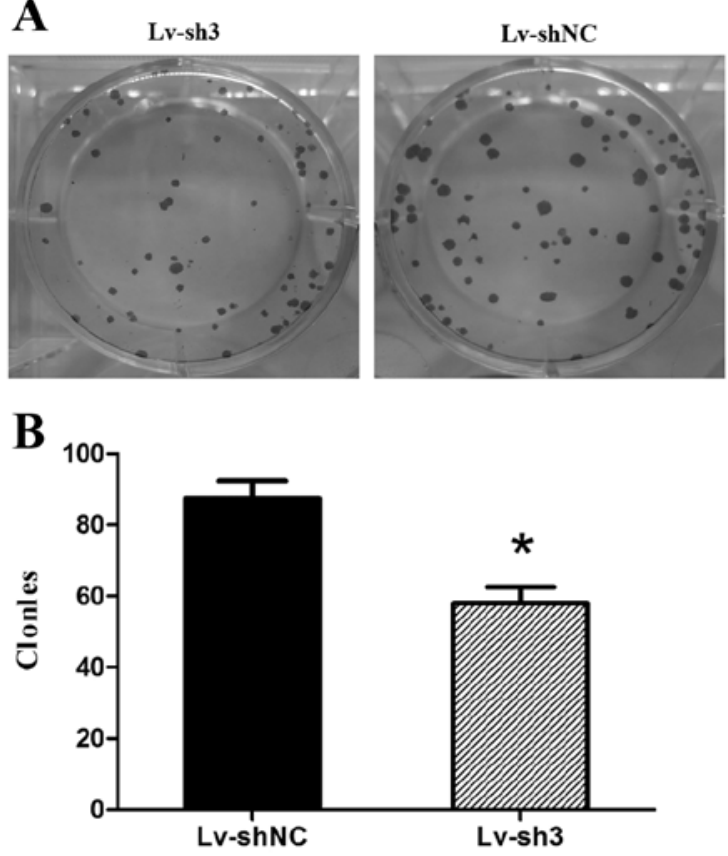

Figure 6. ICAM-1 silencing reduces the colony formation ability of MCF-7 cells. The number and the size of the colonies of MCD-7 cells in Lv-sh3 group compared with that in $\mathrm{Lv}$-shNC group (A and $\mathrm{B}){ }^{*} \mathrm{P}<0.05$ compared with $\mathrm{Lv}$-shNC group.

ysis $(8,31)$. ICAM-1 also reduces ovarian cancer cell growth in the absence of immune cells (32). Other studies confirmed that upregulation of endogenous ICAM-1 can also reduce ovarian cancer cell growth. To date, the exact role of ICAM-1 in breast cancer cells still remains unclear. In this study, we screened the expression level of ICAM-1 in breast cancer tissues with microarrays tissue chip by immunohistochemistry method, the results indicated that ICAM-1 was highly expressed in breast cancer tissues compared with normal breast tissues. We also gathered 35 breast cancer tissues with adjacent non-tumor tissues for further confirmation and the results were in accordance with that of microarrays tissue chip. We selected human breast cancer line MCF-7 with high ICAM-1 expression level as our study subjects and knocked down ICAM-1 expression by lentivirus-mediated RNA interference (RNAi).

We demonstrated that ICAM-1 silencing could inhibit MCF-7 cell metastatic ability in vitro compared with cells infected with Lv-shNC group and MMP-14 expression leval was significantly decreased. One of the key steps in tumor invasion and metastasis is the degradation of the extracellular matrix. MMP-14 known as MT1-MMP was the first identified membrane type MMP (MT-MMPs) that highly expressed in many tumor cell surfaces and play a role in biological processes such as angiogenesis, invasion or proliferation (33), MMP-14 has been recognized as an important MMP involved in dissemination of tumor cells and cancer progression, blockade of MMP-14 can inhibit the metastatic ability of tumor cells (12). Studies have shown that there is a close link between ICAM and MMPs and ICAM-1 can be mediated by MMP-14, and the ectodomain of ICAM-1 is mediated by MMP-14 $(34,35)$. Furthermore, the number of colonies in Lv-sh3 group was markedly reduced compared with Lv-shNC group. Giemsa staining showed that the size of a single colony was smaller, indicating that silencing ICAM-1 could downregulate the adhesion ability between tumor cells and inhibited the colony formation ability of breast cancer cells in vitro.

In conclusion, we showed in the present study that ICAM-1 is overexpress in human breast cancers, while the knockdown of ICAM-1 can suppresses the invasion of breast cancer cells through MMP-14 expression, suggesting that ICAM-1 may serve as a novel and useful prognostic marker and a potential therapeutic target for the treatment of breast cancer.

\section{Acknowledgements}

This study was supported by grants from the National Natural Science Foundation of China (81373185), the Natural Science Foundation of Shandong, China (ZR2009CM019, ZR2014HL058), Shandong Province Department of Education Foundation of China (no. J10LF62); Shandong Province Health Department (no. 2013WS0287, 2014WS0462).

\section{References}

1. Shaukat U, Ismail M and Mehmood N: Epidemiology, major risk factors and genetic predisposition for breast cancer in the Pakistani population. Asian Pac J Cancer Prev 14: 5625-5629, 2013.

2. Ortiz-Martínez F, Sanmartín E, Pomares-Navarro E, PérezBalaguer A, Andrés L, Sánchez-Payá J, Aranda FI, Lerma E and Peiró G: Osteopontin regulates VEGFA and ICAM-1 mRNA expression in breast carcinoma. Am J Clin Pathol 143: 812-822, 2015.

3. Fan L, Strasser-Weipp K, Li J-J, St Louis J, Finkelstein DM, Yu K-D, Chen W-Q, Shao Z-M and Goss PE: Breast cancer in China. Lancet Oncol 15: e279-e289, 2014. http://www.thelancet. com/journals/lanonc/article/PIIS1470-2045\%2813\%2970567-9/ abstract.

4. Kaulfuss S, Herr AM, Büchner A, Hemmerlein B, Günthert AR and Burfeind P: Leupaxin is expressed in mammary carcinoma and acts as a transcriptional activator of the estrogen receptor $\alpha$. Int J Oncol 47: 106-114, 2015.

5. Müller V, Fuxius S, Steffens CC, Lerchenmüller C, Luhn B, Vehling-Kaiser U, Hurst U, Hahn LJ, Soeling U, Wohlfarth T, et al: Quality of life under capecitabine (Xeloda ${ }^{\circledR}$ ) in patients with metastatic breast cancer: Data from a German non-interventional surveillance study. Oncol Res Treat 37: 748-755, 2014.

6. Ramos TN, Bullard DC and Barnum SR: ICAM-1: Isoforms and phenotypes. J Immunol 192: 4469-4474, 2014.

7. Veitonmäki N, Hansson M, Zhan F, Sundberg A, Löfstedt T, Ljungars A, Li ZC, Martinsson-Niskanen T, Zeng M, Yang Y, et al: A human ICAM-1 antibody isolated by a function-first approach has potent macrophage-dependent antimyeloma activity in vivo. Cancer Cell 23: 502-515, 2013.

8. Haustein M, Ramer R, Linnebacher M, Manda K and Hinz B: Cannabinoids increase lung cancer cell lysis by lymphokineactivated killer cells via upregulation of ICAM-1. Biochem Pharmacol 92: 312-325, 2014.

9. Kotteas EA, Boulas P, Gkiozos I, Tsagkouli S, Tsoukalas G and Syrigos KN: The intercellular cell adhesion molecule-1 (ICAM-1) in lung cancer: Implications for disease progression and prognosis. Anticancer Res 34: 4665-4672, 2014.

10. Martin ES, Cesari R Pentimalli F, Yoder K, Fishel R, Himelstein AL, Martin SE, Godwin AK, Negrini $M$ and Croce CM: The BCSC-1 locus at chromosome 11q23-q24 is a candidate tumor suppressor gene. Proc Natl Acad Sci USA 100: 11517-11522, 2003.

11. Anghel SI, Correa-Rocha R, Budinska E, Boligan KF, Abraham S, Colombetti S, Fontao L, Mariotti A, Rimoldi D, Ghanem GE, et al: Breast cancer suppressor candidate-1 (BCSC-1) is a melanoma tumor suppressor that down regulates MITF. Pigment Cell Melanoma Res 25: 482-487, 2012. 
12. Rossé C, Lodillinsky C, Fuhrmann L, Nourieh M, Monteiro P, Irondelle M, Lagoutte E, Vacher S, Waharte F, Paul-Gilloteaux P, et al: Control of MT1-MMP transport by atypical PKC during breast-cancer progression. Proc Natl Acad Sci USA 111: E1872-E1879, 2014.

13. Sugiyama N, Gucciardo E, Tatti O, Varjosalo M, Hyytiäinen M, Gstaiger M and Lehti K: EphA2 cleavage by MT1-MMP triggers single cancer cell invasion via homotypic cell repulsion. J Cell Biol 201: 467-484, 2013.

14. Yan J, Jiang Y, Ye M, Liu W and Feng L: The clinical value of lymphatic vessel density, intercellular adhesion molecule 1 and vascular cell adhesion molecule 1 expression in patients with oral tongue squamous cell carcinoma. J Cancer Res Ther 10 (Suppl): C125-C130, 2014.

15. Alasehirli B, Oğuz E, Oksuzler E, Koruk I, Oztuzcu S, Ozkara E, Karakok M, Erbagc $\mathrm{AB}$ and Demiryurek AT: Investigation of intercellular adhesion molecules (ICAMs) gene expressions in patients with Barrett's esophagus. Tumour Biol 35: 4907-4912, 2014.

16. Lu J and Jin ML: Short-hairpin RNA-mediated MTA2 silencing inhibits human breast cancer cell line MDA-MB231 proliferation and metastasis. Asian Pac J Cancer Prev 15: 5577-5582, 2014.

17. Liu S, Han L, Wang X, Liu Z, Ding S, Lu J, Bi D, Mei Y and Niu Z: Nephroblastoma overexpressed gene (NOV) enhances RCC cell motility through upregulation of ICAM-1 and COX-2 expression via Akt pathway. Int J Clin Exp Pathol 8: 1302-1311, 2015.

18. Guo P, Huang J, Wang L, Jia D, Yang J, Dillon DA, Zurakowski D, Mao H, Moses MA and Auguste DT: ICAM-1 as a molecular target for triple negative breast cancer. Proc Natl Acad Sci USA 111: 14710-14715, 2014.

19. Jenkinson $C$, Elliott $V$ and Menon $U$, Apostolidou S, Fourkala OE, Gentry-Maharaj A, Pereira SP, Jacobs I, Cox TF, Greenhalf W, et al: Evaluation in pre-diagnosis samples discounts ICAM-1 and TIMP-1 as biomarkers for earlier diagnosis of pancreatic cancer. J Proteomics 113: 400-402, 2015.

20. Liu S, Li N, Yu X, Xiao X, Cheng K, Hu J, Wang J, Zhang D, Cheng $S$ and Liu S: Expression of intercellular adhesion molecule 1 by hepatocellular carcinoma stem cells and circulating tumor cells. Gastroenterology 144: 1031-1041.e10, 2013.

21. Shi X, Jiang J, Ye X, Liu Y, Wu Q and Wang L: Prognostic prediction and diagnostic role of intercellular adhesion molecule-1 (ICAM1) expression in clear cell renal cell carcinoma. J Mol Histol 45: 427-434, 2014

22. Dong Z, Fu S, Xu X, Yang Y, Du L, Li W, Kan S, Li Z, Zhang X, Wang L, et al: Leptin-mediated regulation of ICAM-1 is Rho/ ROCK dependent and enhances gastric cancer cell migration. $\mathrm{Br}$ J Cancer 110: 1801-1810, 2014.

23. Hou CH, Lin FL, Tong KB, Hou SM and Liu JF: Transforming growth factor alpha promotes osteosarcoma metastasis by ICAM-1 and PI3K/Akt signaling pathway. Biochem Pharmacol 89: 453-463, 2014
24. Howard K, Lo KK, Ao L, Gamboni F, Edil BH, Schulick R and Barnett CC Jr: Intercellular adhesion molecule-1 mediates murine colon adenocarcinoma invasion. J Surg Res 187: 19-23, 2014.

25. Liou GY, Döppler H, Necela B, Edenfield B, Zhang L, Dawson DW and Storz P: Mutant KRAS-induced expression of ICAM-1 in pancreatic acinar cells causes attraction of macrophages to expedite the formation of precancerous lesions. Cancer Discov 5: 52-63, 2015.

26. Strell C, Lang K, Niggemann B, Zaenker KS and Entschladen F: Neutrophil granulocytes promote the migratory activity of MDA-MB-468 human breast carcinoma cells via ICAM-1. Exp Cell Res 316: 138-148, 2010.

27. Viola K, Kopf S, Huttary N, Vonach C, Kretschy N, Teichmann M, Giessrigl B, Raab I, Stary S, Krieger S, et al: Bay11-7082 inhibits the disintegration of the lymph-endothelial barrier triggered by MCF-7 breast cancer spheroids; the role of ICAM-1 and adhesion. Br J Cancer 108: 564-569, 2013.

28. Ogawa Y, Hirakawa K, Nakata B, Fujihara T, Sawada T, Kato Y, Yoshikawa $\mathrm{K}$ and Sowa M: Expression of intercellular adhesion molecule-1 in invasive breast cancer reflects low growth potential, negative lymph node involvement, and good prognosis. Clin Cancer Res 4: 31-36, 1998.

29. Budinsky AC, Brodowicz T, Wiltschke C, Czerwenka K, Michl I, Krainer M and Zielinski CC: Decreased expression of ICAM-1 and its induction by tumor necrosis factor on breast-cancer cells in vitro. Int J Cancer 71: 1086-1090, 1997.

30. Ren Z, Kang W, Wang L, Sun B, Ma J, Zheng C, Sun J, Tian Z, Yang $\mathrm{X}$ and Xiao W: E2F1 renders prostate cancer cell resistant to ICAM-1 mediated antitumor immunity by NF- $\mathrm{kB}$ modulation. Mol Cancer 13: 84, 2014.

31. Ramer R, Bublitz K, Freimuth N, Merkord J, Rohde H, Haustein M, Borchert P, Schmuhl E, Linnebacher M and Hinz B: Cannabidiol inhibits lung cancer cell invasion and metastasis via intercellular adhesion molecule-1. FASEB J 26: 1535-1548, 2012.

32. de Groote ML, Kazemier HG, Huisman C, van der Gun BTF, Faas MM and Rots MG: Upregulation of endogenous ICAM-1 reduces ovarian cancer cell growth in the absence of immune cells. Int J Cancer 134: 280-290, 2014.

33. Lu H, Hu L, Yu L, Wang X, Urvalek AM, Li T, Shen C, Mukherjee D, Lahiri SK, Wason MS, et al: KLF8 and FAK cooperatively enrich the active MMP14 on the cell surface required for the metastatic progression of breast cancer. Oncogene 33: 2909-2917, 2014

34. Essick E, Sithu S, Dean W and D'Souza S: Pervanadate-induced shedding of the intercellular adhesion molecule (ICAM)-1 ectodomain is mediated by membrane type- 1 matrix metalloproteinase (MT1-MMP). Mol Cell Biochem 314: 151-159, 2008.

35. Park JK, Park SH, So K, Bae IH, Yoo YD and Um HD: ICAM-3 enhances the migratory and invasive potential of human non-small cell lung cancer cells by inducing MMP-2 and MMP-9 via Akt and CREB. Int J Oncol 36: 181-192, 2010. 